\title{
Effects of Addition of Titanium and Boron on Columnar Austenite Grain in Carbon Steel
}

\author{
Masayoshi SASAKI, ${ }^{1)}$ Kiyotaka MATSUURA, ${ }^{21}$ Kenichi OHSASA ${ }^{21}$ and Munekazu OHNO ${ }^{21}$ \\ 1) Formerly Graduate Student, Hokkaido University. Now at Sumitomo Metal Industries, Ltd., Minato, Wakayama, $640-8555$ \\ Japan. 2) Graduate School of Engineering, Hokkaido University, Kita 13 Nishi 8, Kita-ku, Sapporo 060-8628 Japan.
}

(Received on April 3, 2009; accepted on April 23, 2009; originally published in Tetsu-to-Hagané, Vol. 94, 2008, No. 9, pp. 331-335)

\begin{abstract}
Effects of titanium and boron addition on columnar austenite grain structure of S45C steel have been investigated in casting experiments with different cooling rates of 4.50 and $16.67^{\circ} \mathrm{C} / \mathrm{s}$. Without addition of these elements, the columnar austenite grains develop over the whole sample under the present casting conditions. The addition of titanium and boron induces formation of equiaxed austenite grains and, importantly, fully equiaxed austenite structure was observed in the sample with $0.2 \mathrm{~mol} \% \mathrm{Ti}$ and $0.4 \mathrm{~mol} \% \mathrm{~B}$. The microstructural observations indicated that this behavior of austenite structure stems from the columnar-toequiaxed transition of ferrite dendrite structure. The addition of these elements, furthermore, leads to refinement of the columnar austenite grains, which is ascribable to pinning effect of boron nitride and titanium carbonitride.
\end{abstract}

KEY WORDS: carbon steel; casting; austenite structure; grain refinement; columnar-to-equiaxed transition.

\section{Introduction}

As-cast austenite $(\gamma)$ grain size is one of the most important factors to be controlled during continuous casting process of carbon steel in the light of its influence on surface cracking sensitivity of the continuously cast slabs and their deformation behavior in the subsequent hot rolling process. It was reported that the surface crack propagates from the surface to inward of the slab along the boundary of coarse columnar $\gamma$ grains. ${ }^{1)}$ This crack propagation is essentially attributed to a decrease in ductility in $\gamma$ and/or $\alpha+\gamma$ phase fields. Hence, the control of $\gamma$ grain size and the morphology is important issue in steel industries. ${ }^{2)}$

Our recent work on the solidification process of $\mathrm{S} 45 \mathrm{C}$ steel cooled at $0.028^{\circ} \mathrm{C} / \mathrm{s}^{3)}$ revealed that the addition of titanium and boron conduces to the grain refinement of as-cast $\gamma$ grain structure. The $\gamma$ grain size was reduced down to a size comparable to the secondary Dendrite Arm Spacing (DAS). It was considered that this effect should be ascribable to the formation of pinning particles composed of titanium or boron at inter-dendritic positions. This was supported by the result that the $\gamma$ grain size was reduced by reducing the secondary DAS with a high cooling rate. It should be noted that these findings were obtained in slow cooling process with small temperature gradients where the as-cast $\gamma$ grain structure consists of the equiaxed grains. As mentioned above, the coarse columnar $\gamma$ grain structure develops during the continuous casting process and, however, the effect of titanium and boron addition on the columnar grain structure has not been clarified.

It was demonstrated that the temperature gradient at $\delta \rightarrow \gamma$ transformation front plays a dominant role in the morphology of $\gamma$ grain structure and a large temperature gradient results in the development of the columnar structure. ${ }^{4)}$ In this study, we investigate the effect of titanium and boron addition on the columnar $\gamma$ grain structure by means of casting experiments where a large temperature gradient is involved during the solidification process. This effect is discussed in terms of the correlation between the $\gamma$ grain and dendrite structures.

\section{Experimental Procedures}

The chemical composition of the S45C steel rod employed in this study is shown in Table 1. The titanium and boron were added to the $\mathrm{S} 45 \mathrm{C}$ steel. In our previous study on the slow cooling process, ${ }^{3)}$ the molar ratio of the added titanium and boron was fixed to be $1: 2$ with the aim of yielding $\mathrm{TiB}_{2}$ phase as a pining particle material. In this study, also, the molar ratio was taken to be $1: 2$. The amount of addition of these elements is specified by $x$ $\mathrm{mol}_{0} \mathrm{TiB}_{2}$ in this paper and $x$ was varied from 0 to 0.5 . In order to expose the dendrite structure by the use of Oberhoffer's reagent, $0.02 \mathrm{wt} \%$ of phosphorous was added to the steel. The steel sample of about $350 \mathrm{~g}$ was put into an alumina crucible with an inner diameter of $30 \mathrm{~mm}$ and a depth of $90 \mathrm{~mm}$ and it was melted at $1550^{\circ} \mathrm{C}$ in a $\mathrm{SiC}$ electric furnace filled with argon gas of purity higher than $99.999 \%$.

Table. 1. Chemical composition of commercial S45C steel rod employed in this study (wt $\%$ ).

\begin{tabular}{ccccccccc}
\hline & $\mathrm{C}$ & $\mathrm{N}$ & $\mathrm{Si}$ & $\mathrm{Mn}$ & $\mathrm{P}$ & $\mathrm{S}$ & $\mathrm{Al}$ & $\mathrm{O}$ \\
\hline $\mathrm{S} 45 \mathrm{C}$ & 0.45 & 0.0037 & 0.28 & 0.78 & 0.014 & 0.018 & 0.002 & 0.0114 \\
\hline
\end{tabular}



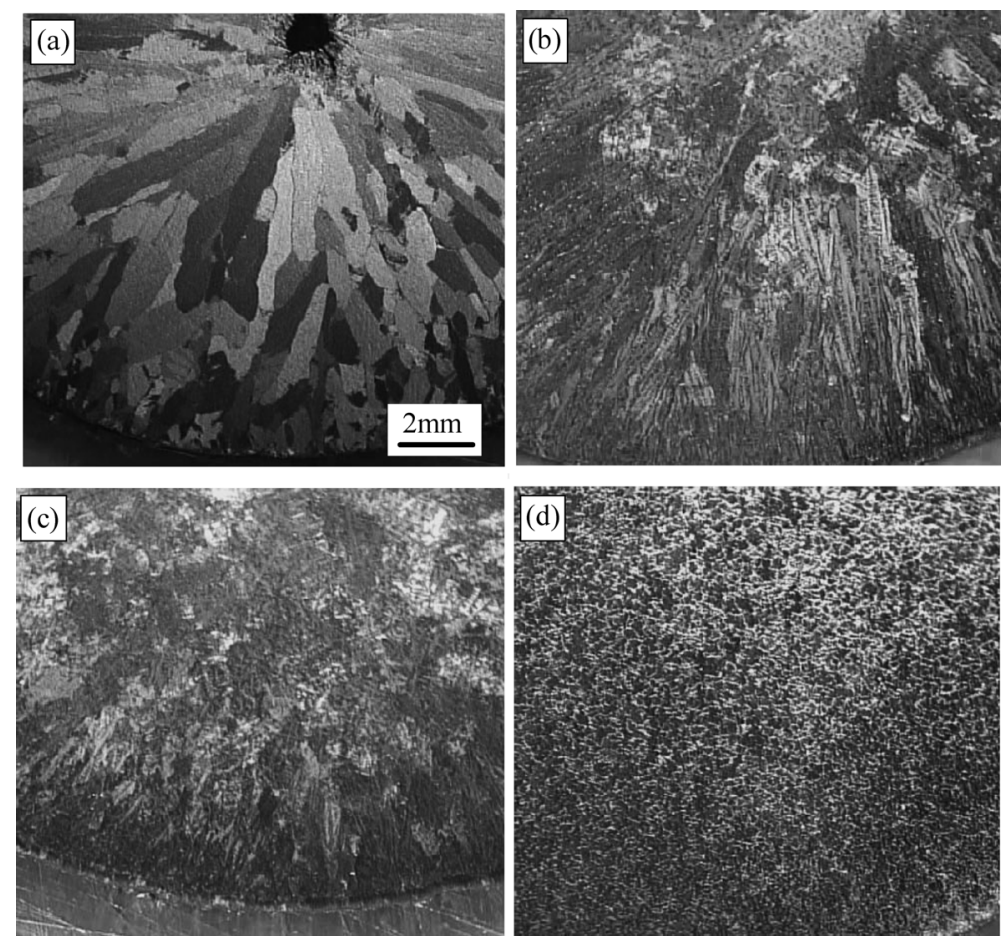

Fig. 1. Austenite grain structures cooled at $\dot{T}=4.50^{\circ} \mathrm{C} / \mathrm{s}$ (a) without addition of $\mathrm{Ti}$ and $\mathrm{B}$, (b) with $0.02 \mathrm{~mol} \% \mathrm{Ti}$ and $0.04 \mathrm{~mol} \% \mathrm{~B}$, (c) with $0.1 \mathrm{~mol} \%$ Ti and $0.2 \mathrm{~mol} \% \mathrm{~B}$, and (d) with $0.2 \mathrm{~mol} \%$ Ti and $0.4 \mathrm{~mol} \% \mathrm{~B}$

After holding the sample for $1 \mathrm{~h}$ at $1550^{\circ} \mathrm{C}$, two types of casting experiments were carried out as follows.

\section{(1) Casting into an Alumina Mold of $800^{\circ} \mathrm{C}$}

The alumina mold with an inner diameter of $30 \mathrm{~mm}$ and a depth of $90 \mathrm{~mm}$ was kept at $800^{\circ} \mathrm{C}$ in an electric furnace for $1 \mathrm{~h}$. The crucible was taken out from the furnace and then put on a refractory brick and the melted steel sample was immediately poured into the alumina mold. After pouring, the B-type thermocouple was inserted into the poured steel at the center. When the monitored temperature decreased down to $1100^{\circ} \mathrm{C}$, the sample was quenched into strongly stirred iced water.

(2) Casting into a Stainless Steel Mold of Room Temperature

The melted steel sample was poured into the stainless steel mold held at the room temperature. The inner diameter and depth of the mold were $30 \mathrm{~mm}$ and $100 \mathrm{~mm}$, respectively. The B-type thermocouple was put at the center of the sample to measure the temperature. The sample was similarly water-quenched from $1100^{\circ} \mathrm{C}$.

The temperature for completion of transition into $\gamma$ single phase, $T_{\gamma}$, was measured from the cooling curve obtained in each casting experiment. We defined the cooling rate by averaging the cooling rate in the temperature range between $T_{\gamma}$ and $T_{\gamma}-100^{\circ} \mathrm{C}$. The cooling rates, $T$, for the casting experiments (1) and (2) were calculated to be $4.50^{\circ} \mathrm{C} / \mathrm{s}$ and $16.67^{\circ} \mathrm{C} / \mathrm{s}$, respectively. The sample ingot has a columnar shape with a diameter of $30 \mathrm{~mm}$ and a height of $80 \mathrm{~mm}$. The horizontal section at middle of height was subjected to the metallographic investigations. The size of columnar $\gamma$ grain was characterized by the long axis diameter along radial direction and the short axis diameter along the direction normal to the long axis. The dendrite structure and inclusion particles were also investigated on the same section.

\section{Results and Discussions}

Figure 1 shows as-cast $\gamma$ grain structures in samples obtained at $\dot{T}=4.5^{\circ} \mathrm{C} / \mathrm{s}$. In the sample without addition of titanium and boron (Fig. 1(a)), the columnar $\gamma$ grains develop along the radial direction from the mold side into inward of the ingot. The columnar grains develop even in the center region. On the other hand, when the titanium and boron were added, the equiaxed $\gamma$ grains exist in the center region, especially, the fine equiaxed $\gamma$ grain structure forms over the whole observation section in the sample with $0.2 \mathrm{~mol} \% \mathrm{Ti}$ and $0.4 \mathrm{~mol} \% \mathrm{~B}$ (Fig. 1(a)). The titanium and boron addition leads to formation of fine equiaxed $\gamma$ grain structure.

In addition to the formation of equiaxed $\gamma$ grains, the titanium and boron addition induced the Columnar-toEquiaxed Transition (CET) of dendrite structure. Figure 2 represents the $\gamma$ grain structure (micrograph of the upper part) in the sample with $0.05 \mathrm{~mol} \% \mathrm{Ti}$ and $0.1 \mathrm{~mol} \% \mathrm{~B}$. Also the dendrite structure in the corresponding region of the sample is given in the lower part of Fig. 2. The dashed lines in the central part of each micrograph indicate the position where the structure changes from the columnar to equiaxed shape. It was observed in all the samples that this position for the $\gamma$ structure approximately coincides with the one for the dendrite structure. The same is true in the other casting samples with $\dot{T}=16.67^{\circ} \mathrm{C} / \mathrm{s}$. On the other hand, it was found in the previous paper ${ }^{3}$ that when the cooling rate is $2.25^{\circ} \mathrm{C} / \mathrm{s}$, the columnar dendrite structure forms near the mold wall, although the columnar $\gamma$ structure was not observed even in the vicinity of the mold wall. This implies that the formation of columnar $\gamma$ grain is not 


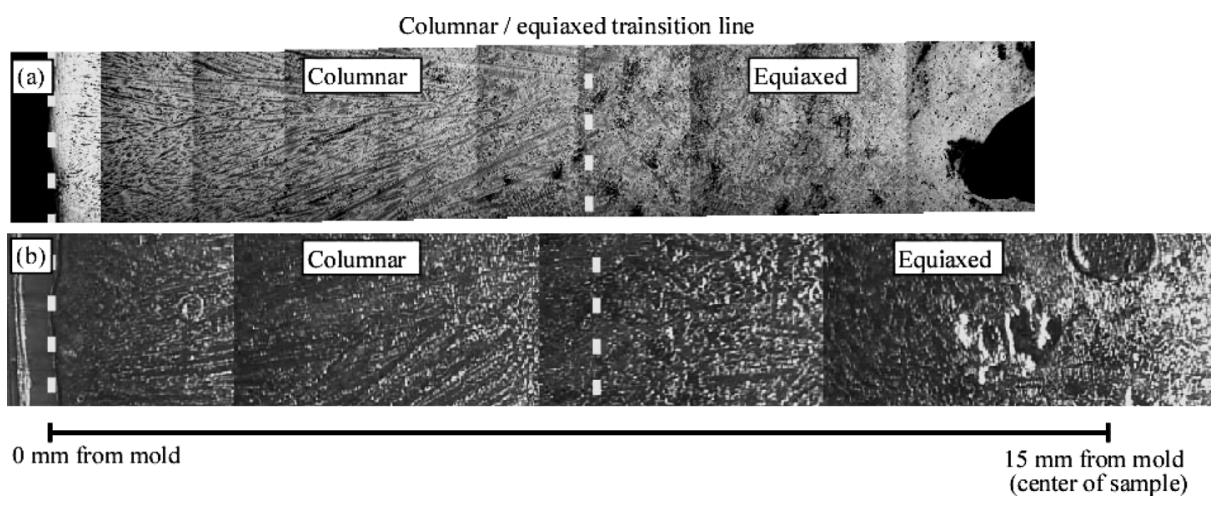

Fig. 2. Comparison between (a) dendrite and (b) austenite grain structures of sample cooled at $\dot{T}=4.50^{\circ} \mathrm{C} / \mathrm{s}$. The columnar to equiaxed transition region is indicated by dashed lines in the center of each micrograph.

mainly ascribable to the morphology of the dendrite structure but to the temperature gradient at the front of the $\gamma$ grain formation, as discussed in Ref. 4). In contrast, the present results demonstrated that the fraction of columnar $\gamma$ grain structure is closely associated with the fraction of columnar dendrite structure. In this regard, the effect of the titanium and boron addition on the dendrite structure was discussed in more detail below.

We measured the length of the region for columnar dendrite structure along the radial direction of the ingot. Then, this length was divided by the radius of the ingot, $15 \mathrm{~mm}$, to obtain the fraction of the columnar dendrite region. The dependence of this fraction on the titanium and boron addition is shown in Fig. 3 where data for $\dot{T}=2.25^{\circ} \mathrm{C} / \mathrm{s}$ obtained in the previous work $^{3)}$ are also presented. In the sample without titanium and boron cooled at $\dot{T}=4.50$ and $16.67^{\circ} \mathrm{C}$ $/ s$, the columnar dendrite structure forms over the entire region. The fraction of the columnar dendrite is reduced by the addition of titanium and boron. The fraction of the columnar dendrite at $\dot{T}=16.67^{\circ} \mathrm{C} / \mathrm{s}$ is always larger than the one at $\dot{T}=4.50^{\circ} \mathrm{C} / \mathrm{s}$. This is because the solidification process at $\dot{T}=16.67^{\circ} \mathrm{C} / \mathrm{s}$ involves larger temperature gradients which prompt development of the columnar dendrite. In the case of $\dot{T}=2.25^{\circ} \mathrm{C} / \mathrm{s}$, furthermore, the fraction of the columnar dendrite region decreases with addition of titanium and boron. As already mentioned, the $\gamma$ structure in the samples at $\dot{T}=2.25^{\circ} \mathrm{C} / \mathrm{s}$ consists of the equiaxed grains over the entire region. This fact implies that the temperature gradient during $\gamma$ formation process is relatively low compared with that during dendrite formation and the condition for formation of equiaxed $\gamma$ grains could be satisfied. ${ }^{4)}$

It is considered that the formation of equiaxed dendrite structure due to titanium and boron addition originates from the extension of constitutional undercooling region by segregation of solute element ahead of the developing dendrite and/or formation of some particles acting as nucleation site for equiaxed dendrite. As discussed later, the $\mathrm{Ti}(\mathrm{C}, \mathrm{N})$ and $\mathrm{BN}$ were observed in the sample with titanium and boron addition. It was reported in Ref. 6) that the $\mathrm{Ti}(\mathrm{C}, \mathrm{N})$ is very effective in promoting heterogeneous nucleation of $\delta$-Fe phase, because of low disregistry between $\mathrm{Ti}(\mathrm{C}, \mathrm{N})$ and $\delta$-Fe phases. In the studies on ferritic stainless steels, ${ }^{7}$ furthermore, it was demonstrated that the $\mathrm{Ti}(\mathrm{C}, \mathrm{N})$ particles give rise to the CET of $\delta$ solidification. Therefore, the CET of the dendrite structure observed in this study

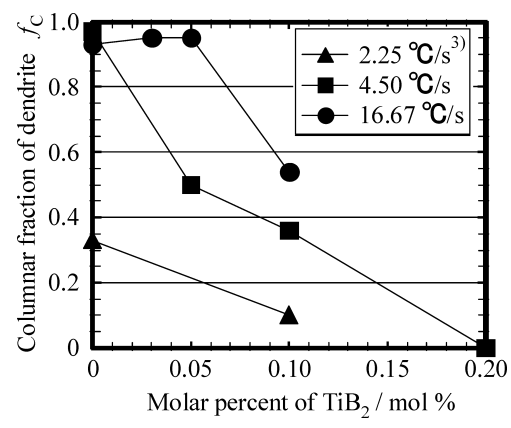

Fig. 3. Effect of addition of $\mathrm{Ti}$ and $\mathrm{B}$ on fraction of columnar dendrite.

should be associated with the $\operatorname{Ti}(\mathrm{C}, \mathrm{N})$ particles. As discussed in Ref. 4), however, the formation of equiaxed $\gamma$ grain structure does not necessarily results from the equiaxed dendrite structure. On the other hand, a strong correlation was observed between the formations of equiaxed dendrite and equiaxed $\gamma$ grains in the present results. The formation of equiaxed dendrite in the melt is spatially discontinuous compared with the continuous growth of columnar dendrite from the mold wall. Accordingly, the release of the latent heat due to the nucleation and growth of new equiaxed dendrite is considered to be also spatially discontinuous. This discontinuous heat generation during the $\delta$ solidification process may reduce the temperature gradient during subsequent $\gamma$ formation, which causes the formation of equiaxed $\gamma$ grains. In the present experiment, we measured the temperature only at the center of the sample in order to avoid the influence of the temperature measurement on the solidification process. Thus, we could not further discuss the relation between the temperature gradient and formation of equiaxed $\gamma$ grain structure in the present casing condition. In this regard, the detailed heat transfer analysis on the present system remains as a future work. On the other hand, as reported in the previous paper, ${ }^{3)}$ the addition of titanium and boron yields inclusion particles in the interdenritic region and these particles pin the $\gamma$ grain boundary. Hence, it is considered that the growth of the columnar $\gamma$ grain may be prevented by the pinning particles in the interdendritic region and this leads to the strong correlation between the $\gamma$ grain and dendrite structures.

Next, the dependence of $\gamma$ grain size is discussed. Figure 4 represents the columnar $\gamma$ grain structures in the samples 

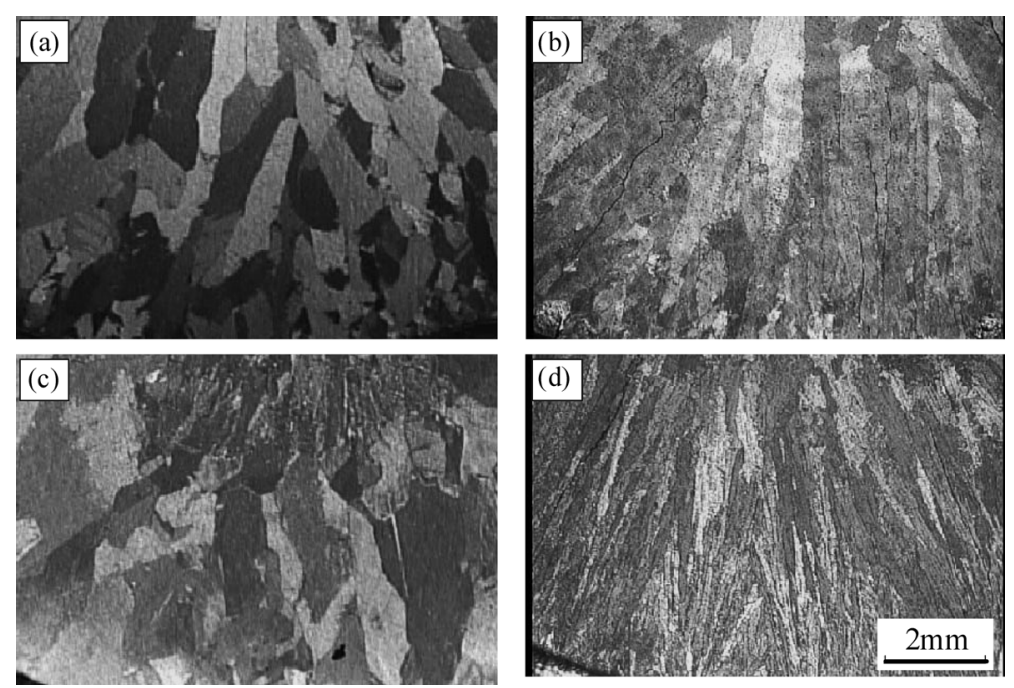

Fig. 4. Columnar austenite grain structures (a) without addition of Ti and $\mathrm{B}$ at $\dot{T}=4.50^{\circ} \mathrm{C} / \mathrm{s}$, (b) $0.1 \mathrm{~mol} \% \mathrm{Ti}$ and $0.2 \mathrm{~mol} \% \mathrm{~B}$ at $\dot{T}=4.50^{\circ} \mathrm{C} / \mathrm{s}$, (c) without addition of $\mathrm{Ti}$ and $\mathrm{B}$ at $\dot{T}=16.67^{\circ} \mathrm{C} / \mathrm{s}$, and (d) $0.1 \mathrm{~mol} \% \mathrm{Ti}$ and $0.2 \mathrm{~mol} \% \mathrm{~B}$ at $\dot{T}=16.67^{\circ} \mathrm{C} / \mathrm{s}$.

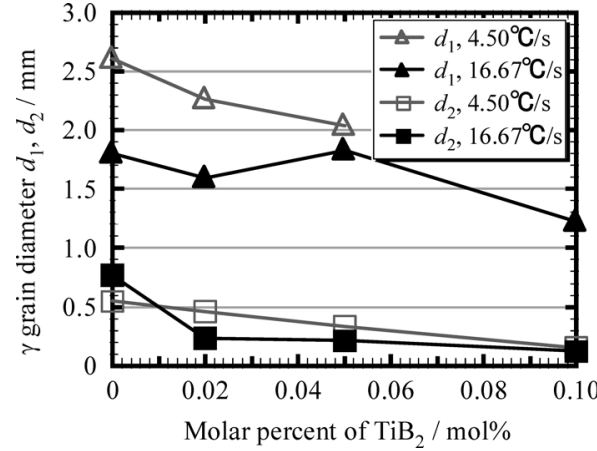

Fig. 5. Effects of addition of $\mathrm{Ti}$ and $\mathrm{B}$ on long axis diameter, $d_{1}$, and short axis diameter, $d_{2}$, of columnar austenite grain.
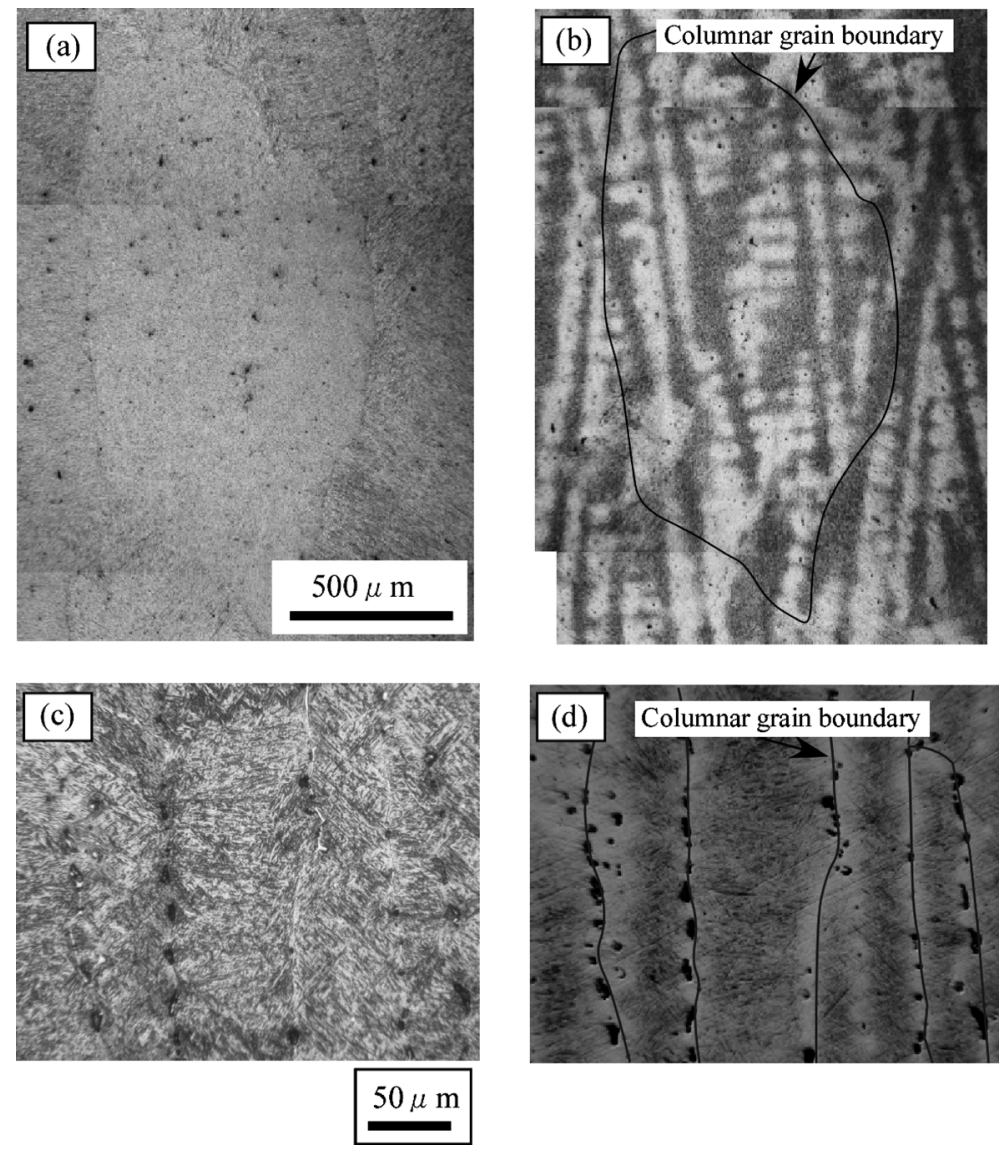

Fig. 6. Comparison between austenite ((a) and (c)) and dendrite ((b) and (d)) structures at the same positions at $\dot{T}=16.67^{\circ} \mathrm{C} / \mathrm{s}$. The micrographs (a) and (b) indicate the structures without addition of $\mathrm{Ti}$ and $\mathrm{B}$, while the micrographs (c) and (d) represent the structures with addition of $0.1 \mathrm{~mol} \% \mathrm{Ti}$ and $0.2 \mathrm{~mol} \% \mathrm{~B}$.

cooled at 4.50 and $16.67^{\circ} \mathrm{C} / \mathrm{s}$. It is seen that the columnar grain size is reduced by the addition of titanium and boron. The effects of the titanium and boron addition on the long axis diameter $d_{1}$ and short axis diameter $d_{2}$ of the columnar $\gamma$ grain are shown in Fig. 5. At each cooling rate, the long and short axis diameters gradually decrease with the increase in titanium and boron concentrations. The columnar dendrite and $\gamma$ grain structures at the same position are shown in Fig. 6. In the sample without titanium and boron $((a),(b))$, the $\gamma$ grains are coarse and one grain covers several dendrites growing in the same direction. In contrast, there is one-to-one correspondence between one $\gamma$ grain and one dendrite in the sample with titanium and boron ((c), (d)). As shown in Fig. 7, the small particles exist in- 


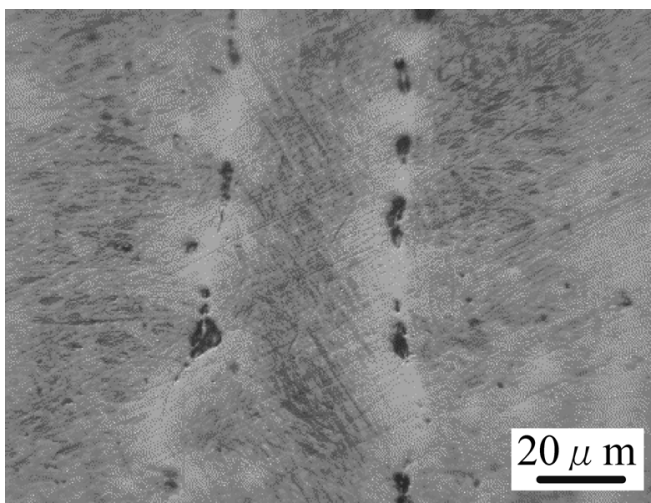

Fig. 7. Pinning particles existing between primary dendrite arms in the sample cooled at $\dot{T}=16.67^{\circ} \mathrm{C} / \mathrm{s}$.

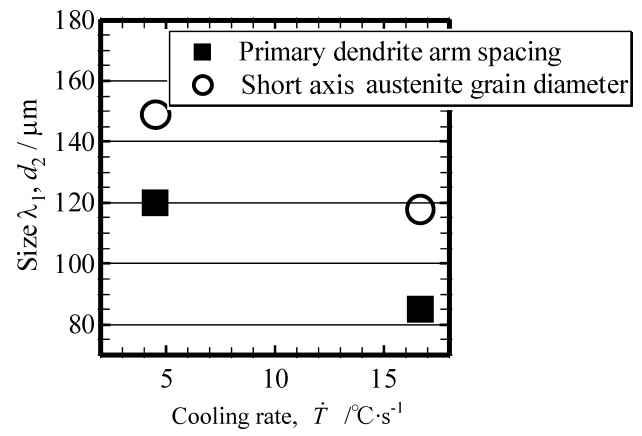

Fig. 8. Effects of cooling rate on primary dendrite arm spacing and short axis diameter of columnar austenite grain in the sample with $0.1 \mathrm{~mol} \%$ Ti and $0.2 \mathrm{~mol} \% \mathrm{~B}$.

between the primary dendrite arms and these particles are considered to pin the $\gamma$ grain boundary. The Energy Dispersed Spectroscopy, or EDS, analysis revealed that these particles were not $\mathrm{TiB}_{2}$ which we initially expected but $\mathrm{Ti}(\mathrm{C}, \mathrm{N})$ and BN. Figure 8 represents the cooling rate dependence of the primary dendrite arm spacing, $\lambda_{1}$. Since $\lambda_{1}$ is proportional to square of inverse of cooling rate or square of solidification time, ${ }^{8-11)} \lambda_{1}$ decreases with the increase in cooling rate. In Fig. 8, also, the short axis diameter of columnar $\gamma$ grain $d_{2}$ is indicated. While the short axis diameter $d_{2}$ always takes higher value than $\lambda_{1}, d_{2}$ decreases in accordance with decrement of $\lambda_{1}$.

Based on all the results thus described, we considered the following mechanism regarding the effect of titanium and boron addition on the as-cast $\gamma$ grain structure. The schematic illustration is given in Fig. 9. The addition of titanium and boron induces the nucleation of equiaxed $\delta$ dendrite ahead of the columnar dendrite and the CET of $\delta$ solidification occurs. Accordingly, the temperature gradient during $\gamma$ formation is changed to satisfy the condition for the formation of equiaxed $\gamma$ grains, or possibly the $\mathrm{Ti}(\mathrm{C}, \mathrm{N})$ and $\mathrm{BN}$ particles form in-between the dendrite arms and the pinning effect of these particles lead to the formation of equiaxed $\gamma$ grains. Then, these particles prevent the $\gamma$ grain growth. Accordingly, the strong correlation exists between the dendrite and $\gamma$ grain structures. In fact, it was shown in this study that the reduction of dendrite size by increasing cooling rate results in refinement of $\gamma$ grain structure.

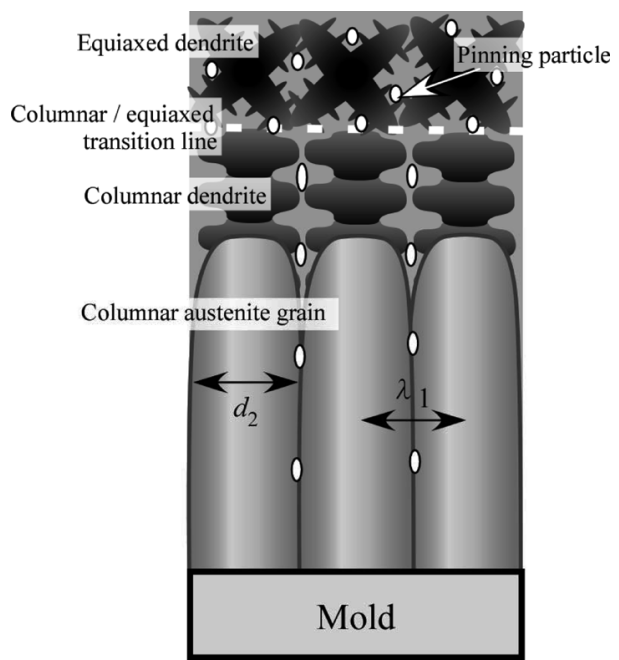

Fig. 9. Schematic picture illustrating the effect of $\mathrm{Ti}$ and $\mathrm{B}$ on solidification process.

\section{Conclusions}

We investigated the effects of titanium and boron addition on as-cast $\gamma$ grain structure of S45C steel by means of the casting experiment with different cooling rates of 4.50 and $16.67^{\circ} \mathrm{C} / \mathrm{s}$. The following results were found,

(1) The columnar $\gamma$ grain structure forms over the whole observation section at each cooling rate in the samples without the addition of titanium and boron.

(2) The addition of titanium and boron reduces the fractions of columnar dendrite and columnar $\gamma$ grain structures. The position where the structure changes from columnar to equiaxed shape is almost identical in both the dendrite and $\gamma$ grain structures.

(3) The equiaxed $\gamma$ grains develop over the whole observation area with $0.2 \mathrm{~mol} \% \mathrm{Ti}$ and $0.4 \mathrm{~mol} \% \mathrm{~B}$.

(4) The long and short axis diameters of the columnar $\gamma$ grain decrease with the increase in titanium and boron concentrations.

(5) The increment of cooling rate leads to the reduction of primary dendrite arm spacing and, accordingly, the short axis diameter of the columnar $\gamma$ grain decreases.

\section{REFERENCES}

1) L. Schimidt and A. Josefsson: Scand. J. Metall., 3 (1974), 193.

2) Y. Maehara, K. Yasumoto, Y. Sugitani and K. Gunji: Tetsu-toHagané, 70 (1984), S904.

3) M. Sasaki, K. Ohsasa, M. Kudoh and K. Matsuura: ISIJ Int., 48 (2008), 340.

4) K. Matsuura, Y. Itoh and K. Matsubara: Tetsu-to-Hagané, 76 (1990) 5,71 .

5) H. Fredriksson and J. Stjerndahl: Met. Sci., 16 (1982), 575.

6) B. L. Bramfitt: Metall. Trans., 1 (1970), 1987.

7) T. Koseki and H. Inoue: J. Jpn. Inst. Met., 65 (2001), 644.

8) M. C. Flemings: Mod. Cast., 46 (1964), 353.

9) T. Z. Kattamis and M. C. Flemings: Trans. Metall. Soc. AIME, 236 (1966), 1523.

10) M. C. Flemings, R. V. Barone, and H. D. Brody: MIT Interim Report, Contract No.DA-19-020-AMC-5443 (1976).

11) M. C. Flemings, D. R. Poirier, R. V. Barone and H. D. Brody: J. Iron Steel Inst., 208 (1970), 37.

12) Y. Maehara, K. Yasumoto, Y. Sugitani and K. Gunji: Tetsu-toHagané, 71 (1985), 1534. 